\title{
367
}

Symposium on Pediatric Surgery

\section{Transplantation in Children}

\author{
Richard Weil, III, M.D..* \\ Charles W. Putnam, MD., $†$ \\ Kendrick A. Porter, MD.,+
} and Thomas E. Starzl. M.D., Ph.D. $\S$

The vascularized organs most often transplanted in children are the kidney and liver. A small number of infants or children with untreatable congenital heart lesions who die early in life could possibly benefit from heart transplants, but there has been little experience with heart replacement in the pediatric age group. An occasional infant with a short bowel syndrome resulting from a complication of a congenital intestinal malformation might benefit from small bowel transplantation. but experimental bowel transplants in the laboratory have been so unsuccessful that this approach has rarely been attempted in pediatric patients. Bone marrow transplants are done in most centers by pediatric hematologists rather than by surgeons, and that form of transplantation will not be considered in this report.

The following analysis of kidney and liver transplantation in children will focus on the experience at the University of Colorado Medical Center. The pediatric kidney transplantation cases previously reported in $1966^{*}$ and $1971^{3}$ will be updated, with a minimum postoperative follow-up of 6 years. The comments on liver transplantation will be

From the Departments of Surgery. the University of Colorado Medical Center and the Veteran's Adıninistration Hospital. Denver. and the Department of Pathology. St. Mary's Hospital and Medical School. London.

Associate Professor of Surgery. University of Colorado Medical Center.

- Assistant Professor of Surgery. University of Colorado Medical Center

: Professor of Pathology. St. Mary's Hospital and Medical School. London

§hairman, Department of Surgery, University of Colorado Medical Center: Faculty Scholar of the Josiah Macy Jr. Foundation.

The work was supported by research grants from the Veteran's Administration; by grants AIAm-08898 and AM-07772 from the National Institutes of Health: by grants RR-00051 and RR-00069 from the General Clinical Research Centers Program of the Division of Research Resources. the National Institutes of Health; and by a grant from the Medical Research Council of Great Britain. 
based upon 56 consecutive recipients of orthotopic livers who were 18 years of age or younger at the time of operation and who have a potential follow-up of at least 1 year.

\section{KIDNEY TRANSPLANTATION}

Kidney transplantation was performed in 57 children 3 to 18 years of age between November. 1962 and July, 1969. Twenty-two of these patients were operated upon 10 to 13 years ago and the other 35 cases 6 to 10 years ago.

\section{Conditions of Care}

The methods of transplantation and immunosuppression have been described previously. ${ }^{3+4 \cdot 6 \cdot 11}$ Fifty-five of the children had hemodialysis before transplantation, and 18 had peritoneal dialysis. Almost all of the children had bilateral nephrectomy and splenectomy, either before or at the same time as transplantation. Thymectomy was done in 10 patients. The 22 children treated with renal transplantation between 1962-1965 were given their primary kidneys by living donors. There were 20 living related donors and two living unrelated donors. In the 35 cases transplanted between 1965 and 1969, 25 of the primary homografts were

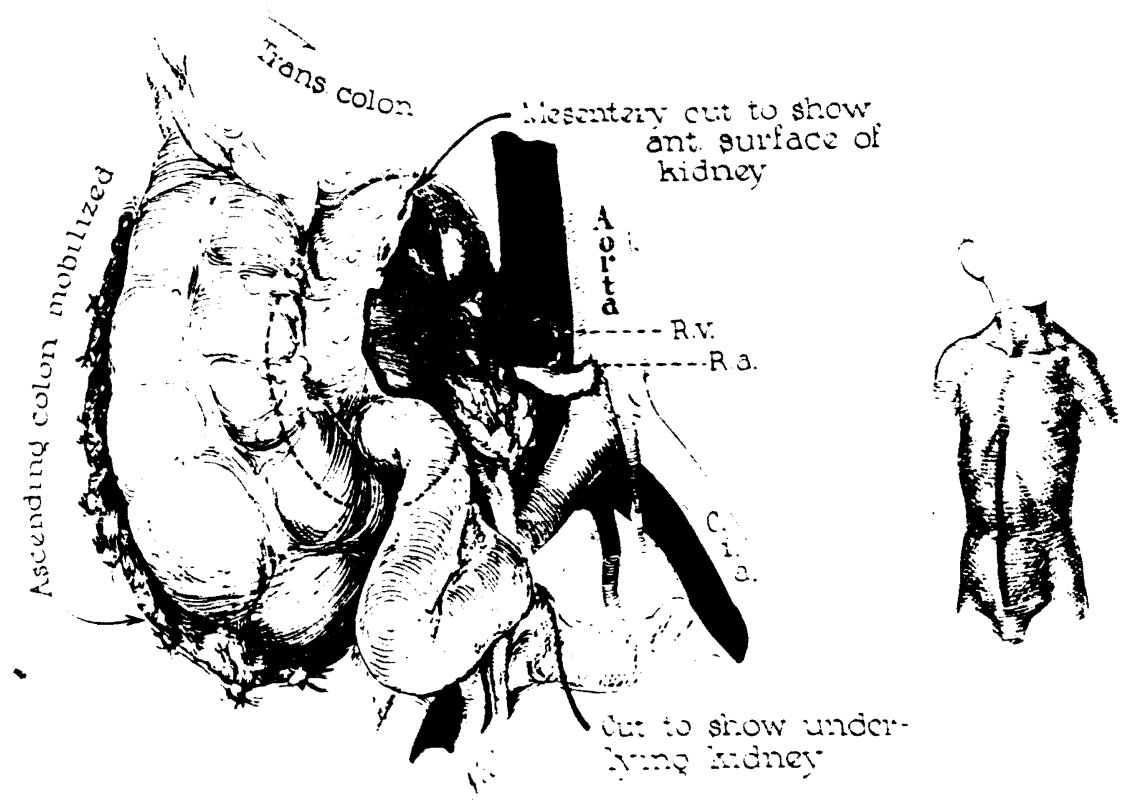

Figure 1. Technique used for transplantation of adult homografts to infants or small children. The entire operation is performed transabdominally. through a midline incision. (Reproduced from Starzl. T. E.. Marchioro. T. L.. Morgan. W. W., and Waddell. W. R.: A technique for use of adult renal homografts in children. Surg. Gynec. Obstet., 119:106. 1964. By permission of Surger: Gynecology \& Obstetrics.) 
Figure 2. A 25-year-old laboratory technician who was the first recipient of a renal homograft in the Denver series, in 1962 . at age 12 years: retrans. plantation was necessary in 1968. Renal function is normal.

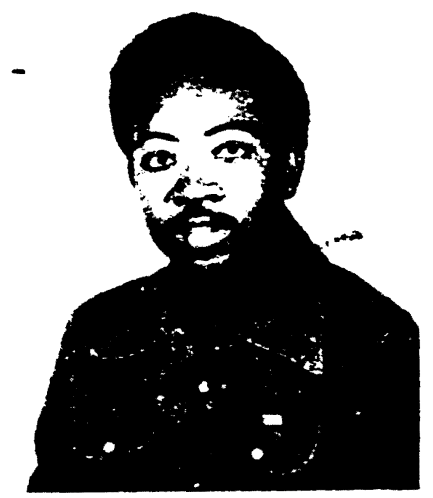

from living related donors and the other 10 first organs were from cadavers. In 11 children the graft was put retrocecally via a transperitoneal approach. because of the small size of these recipients (Fig. 1). The bladder was usable for restoration of urinary tract continuity in all cases. Sixteen of these 57 children have subsequently required retransplantation.

Donor selection by means of histocompatibility testing was started in Denver in October, 1964, and between then and 1966, all donors were chosen by HLA matching. This method of donor selection was discontinued in 1966 because of the lack of correlation between the HLA match and graft survival. Typing was continued thereafter in all cases for the sake of data accumulation. Because of the age of the recipients there were few sibling donors. For example. only one sibling donor was used for the 22 patients transplanted between 1962 and 1965. The most common donors were parents.

Grafts obtained from living donors were perfused immediately after removal with cold lactated Ringer's solution $\left(15^{\circ}\right)$ which contained 50 $\mathrm{mg}$ heparin and $1 \mathrm{gm}$ procaine per liter. Grafts obtained from cadaveric donors were preserved in a variety of ways, all of which included prompt cooling with chilled solutions.

All 57 children received prednisone and azathioprine. The last 28 cases received antilymphocytic globulin (ALG) as well, usually for a period of less than 4 months after transplantation. A few of the earliest patients received actinomycin $C$ and local graft irradiation for scute rejection crises. The first patient in the series who received a homograft, in November. 1962, at the age of 12 years, was subjected to total body irradiation (Fig. 2).

The native kidney disease causing renal failure was not clearly identifiable in all cases. Of the 22 patients transplanted between 1962 and 1965. the original disease was chronic glomerulonephritis in 18 cases, pyelonephritis in three, and polycystic disease in one. Similarly. most of the 35 children transplanted between 1965 and 1969 had chronic glomerulonephritis; there was one case of cystinosis and one case of oxalosis. 


\section{Outcome}

Five primary kidneys were lost in the early postoperative period. One graft which was transplanted from an $\mathrm{A}$ donor into an $\mathrm{O}$ pediatric recipient early in our experience failed immediately from hyperacute rejection. Three grafts were rejected hyperacutely due to presumed or proved preformed antibodies against non-red cell antigens. A fifth graft was removed 3 days after transplantation because of a technical complication.

After follow-ups of 6 to 13 years. 35 (61 per cent) of the 57 children are still living and 34 (60 per cent) have renal function. One is on dialysis (Table 1 ).

Fourteen (64 per cent) of the 22 children originally treated 10 to 13 years ago are alive, five after undergoing retransplantation.

Twenty-one (60 per cent) of the 35 patients transplanted 6 to 10 years ago are alive. Fifteen (60 per cent) of the 25 children whose primary grafts were from related volunteers are still alive, as well as six (60 per cent) of the ten children whose primary grafts were from cadavers. Of the 21 current survivors from the 35 cases of 6 to 10 years ago, 16 still have the original grafts and five bear retransplants.

The greatest mortality was within the first few months postoperatively, although losses occurred as late as 12 years. The leading cause of death was infection. There were two deaths from cerebrovascular accidents. One patient died from a pulmonary embolus.

Unusual causes of death included reticulum cell sarcoma of the brain in a 14-year-old child who died $\bar{i}$ months after transplantation from a relative. One child received her first renal homograft in 1968, her second in 1970, and died in 1973 at the age of 18 years of superior mesenteric arterial occlusion. One 18-year-old boy committed suicide 8 months after successful related transplantation. by jumping through a heavy glass window on the 8th floor of the hospital.

The leading cause of graft failure was rejection. Technical difficulties were rare, accounting for one lost graft in the earlier 22 cases. Three patients are known to have stopped taking immunosuppressive medication, against medical advice. They were 18 to 22 years old when they discontinued medication. and all three lost their grafts to rejection within 6 months after discontinuing azathioprine and prednisone. These grafts had previously been functioning well for 3 years, 6 years. and 7 years respectively. All three patients were successfully retransplanted, but one died 17 months later of hepatitis and bacterial sepsis.

Table 1. Results of Pediatric Kidney Transplantation in 57 Children

\begin{tabular}{|c|c|c|c|c|}
\hline \multirow[b]{2}{*}{ No. OF CASES } & \multirow{2}{*}{$\begin{array}{l}\text { DURATION OF } \\
\text { FOLLOW-UP }\end{array}$} & \multicolumn{2}{|c|}{ DONOR } & \multirow[b]{2}{*}{ NO. LIVING } \\
\hline & & Livins & Cadaver & \\
\hline 22 & 10 to 13 years & $\because 2$ & 0 & $14^{+}(64$ per cent $)$ \\
\hline 35 & 6 to 10 years & .25 & 10 & $21 ; 60$ per cent \\
\hline
\end{tabular}

Two living unrelated donors. All other donors were related.

+ Five living after retransplantation.

:Five living after retransplantation. 
Figure 3. Twelve vears ago this young lady received a renal homograft from her mother. at age 10 years. She is currently enrolled in our university's Child Health Associate Program.

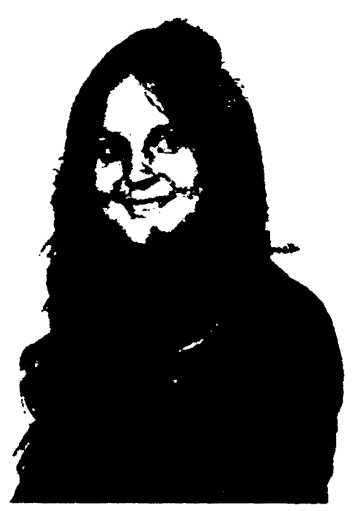

Twelve of the 57 children had one retransplant, one has had three transplants, one has had four transplants, and two have had five transplants. One child with five transplants is alive with a functioning graft 13 years after the original transplantation. The other recipient of five transplants died 3 months after the 5 th transplant. Six of the 16 children who underwent retransplantation have died.

Most of these patients have had some "catchup" growth following transplantation. as we have previously reported, although most have ended up with short stature. A few children have experienced bony complications in addition to growth retardation, including atrophy of the femoral head in five patients and compression fractures of lower thoracic vertebrae in one patient.

In spite of the additional burdens imposed on these children by endstage renal failure. hemodialysis, transplantation, and immunosuppression. many of the 35 surviving patients have been able to develop into well-adjusted young adults. All of the 22 survivors, whose current ages range from 14 to 30 years, are now working full-time or are going to school full-time or are raising families. One 22-year-old girl, who received a transplant 12 years ago from her mother and is in excellent health, recently married a transplant surgeon (Fig. 3).

\section{LIVER TRANSPLANTATION}

During the 11-year period 1963 to 1974 approximately 200 patients received liver replacement. Almost 100 of these recipients were from the Denver series, including 56 who were 18 years old or younger at the time of transplantation. The diseased native liver was removed and the cadaveric organ was placed in the normal (orthotopic) anatomic location (Fig. 4). These 56 children are the subject of the following report.

\section{Case Material}

In 40 of the children the cause of liver failure was biliary atresia. The other diagnoses were hepatitis (nine cases). malignant tumor (three 


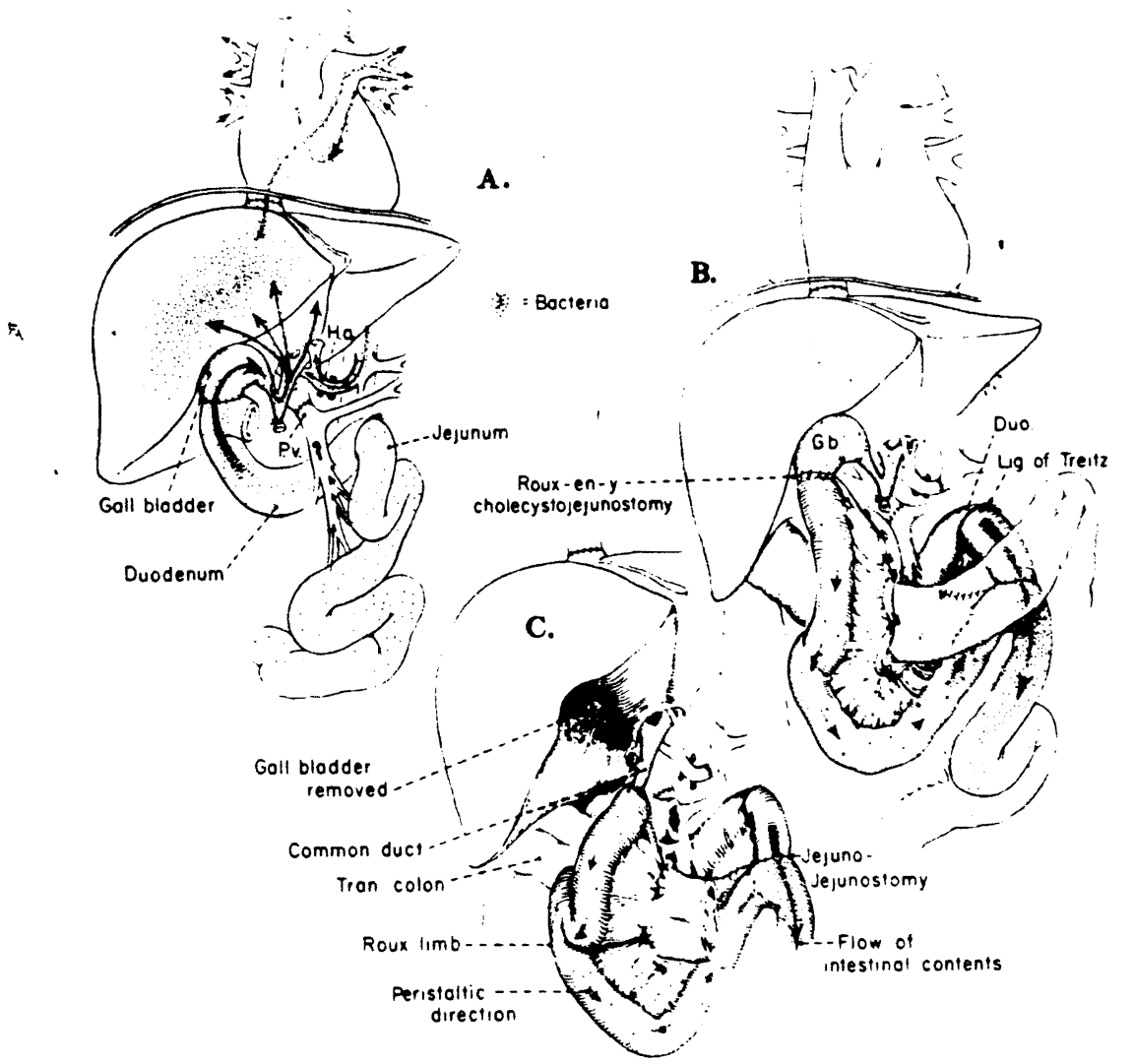

Figure 4. Technique of orthotopic liver transplantation. In pediatric patients, three different kinds of biliary reconstruction have been emploved: $A$. Cholecystoduodenostomy: this simple technique carries the greatest risk of bacterial contamination of the biliany tract. $B$. Roux-en-Y cholecvstojejunostomy: the biliary tract of the homograft is separated from the main gastrointestinal stream by an 18-inch isoperistaltic limb of jejunum. C. Roux-en-Y choledochojejunostomy: the duct-to-bowel anastomosis is simple if the duct has become dilated, as is the case when conversion from $(B)$ to $C$ : is necessary. (Reproduced from Starzl, T. E., Ishikawa. M.. Putnam. C. W.. et al.: Progress in and deterrents to orthotopic liver transplantation: with special reference to survival. resistance to hyperacute rejection, and biliary tract reconstruction. Transplant. Proc.. 6 ; Suppl. 1):129. 1974. U'sed with permission.)

cases), Wilson's disease (two cases), alpha-1-antitrypsin deficiency (one case), and congenital biliary cirrhosis (one case).

At the time of transplantation the mean age of the 40 patients with biliary atresia was $42.0 \pm 37.7$ (S.D.) months. with an age range of 3 to 191 months. Four of these children had survived 7 to 15 years before transplantation and were thought to have intrahepatic atresia because of their longevity. Under the light microscope the livers of these four children showed micronodular biliary cirrhosis. compatible with congenital intrahepatic biliary atresia. Two of these four livers were found to contain hepatoma, which was found in only one of the 36 vounger children transplanted for biliary atresia. 
The mean age of the 16 children transplanted for diseases other than biliary atresia was $12.9 \pm 4.6$ (S.D.) years, with an age range of 1 to 18 rears.

\section{Conditions of Care}

Very young cadaver organ donors are scarce, largely because lethal head trauma is less common in the young child than in the teenager or adult. At the same time, it is important that the donor liver be small enough to fit easily into the peritoneal cavity of the recipient. An oversized organ is difficult to revascularize, because of the relatively fixed distance betwen the suprahepatic vena cava and infrahepatic vena cava in the recipient. In addition. an excessively large graft may cause postoperative respiratory insufficiency by restricting diaphragmatic motion.

The size of the donor (liver) is the major criterion for donor selection. Preformed antibodies in the recipient against the donor's A or B red cell antigens or against the donor's HLA antigens do not seem to have so ominous a prognosis in liver transplantation as in kidney transplantation. Neither of the two children who had liver transplants in the face of preformed anti-red cell antibodies had hyperacute rejection of the graft. such as was described in the section on renal transplantation. However, neither of these children survived for longer than 8 months after transplantation.

The technique of operation has been described.1.12 For the last 2 years, including the last year of this report (1974), biliary drainage of the graft has been established by anastomosis of the gallbladder to the jejunum (Roux-en-y) (Fig. 4B), rather than by cholecystoduodenostomy (Fig. 4A). Choledochojejunostomy (Fig. 4C) or choledochocholedochostomy with $\mathrm{T}$-tube splint have been used in a few cases.

Splenectomy was done in $\mathbf{4 2}$ of the first 56 pediatric cases and during that period was omitted only if this procedure appeared to add excessive risk to the transplant operation; in the last five children included in this report, it was decided preoperatively that splenectomy would not be done.

Immunosuppression for these patients has been described.;. 712 Prednisone, azathioprine, and antilymphocytic globulin were used, and intravenous methylprednisolone was given intermittently for acute rejection episodes.

\section{Outcome}

Biliary Atresia. Twenty-nine of the 40 patients with biliary atresia, died within 6 months of transplantation. Ten patients died within the first 3 postoperative weeks because of vascular occlusions or hemorrhage. Two of these 10 deaths occurred following retransplantation; in one patient the original graft appeared to have been destroyed by viral infection. and in the other patient the original graft from an anencephalic monster appeared to have previously unrecognized intrahepatic biliary atresia.

Five additional early postoperative deaths, within the first 5 post- 
operative weeks, were thought to be due to rejection. These patients were treated with heavy immunosuppression. and infections were important contributory factors in the deaths of almost all of these patients. At autopsy the histology of four of these grafts showed mononuclear cells in the portal tracts and around the central veins, with necrosis of hepatocytes, compatible with acute cellular rejection. The histology of the fifth liver was not characteristic of rejection; therefore, this clinical diagnosis could not be confirmed.

Seven patients died 1 to 3 months after transplantation because of nonvascular technical complications. One patient died of a fungal retroperitoneal abscess following injury to the tail of the pancreas during splenectomy. The other six deaths followed complications related to the biliary tract reconstruction. Four patients with cholecystoduodenostomy developed cystic duct obstruction. and two more had biliary fistulas. At autopsy these six livers showed microscopic evidence of partial biliary obstruction. There was no histologic evidence of rejection.

There were seven deaths 2 to 6 months after transplantation because of infection. Four of these seven deaths were related to partial hepatic infarctions which were thought to be due to occlusion of small branches of the hepatic artery; these areas of infarction became infected. The infectious agents varied in the seven cases and included bacteria. fungi, and viruses.

The 11 patients who survived for more than 6 months after transplantation all survived for at least 6 additional months. Four subsequently died 1 to $3^{1 / 2}$ years after transplantation because of liver damage of uncertain cause. Chronic rejection was probably a major factor in all four of these deaths; hemophilus influenza septicemia and viral hepatitis may have been contributory in two cases. The other seven patients are still alive 1 to 5 years after transplantation (Fig. 5).

Other than Billary Atresia. Seven of the 16 patients died within 6 months of operation. One succumbed in 10 postoperative days with liver necrosis, probably related to hepatic arterial occlusion, although it is possible that this liver was damaged in the donor or while being transferred to the recipient. One patient developed irreversible early rejection of the graft requiring transplantation on the 157 th postoperative day; she died 1 month later of sepsis. There was one additional early death from acute cellular rejection, on the 9 th postoperative day. One patient died on the 64 th postoperative day from sepsis following perforation of a diverticulum of the right colon. There were two additional deaths from nonvascular intraabdominal complications: both patients had partial biliary obstructions and died of sepsis. One patient died of carcinomatosis 143 days after resection of a hepatoma.

Nine (56 per cent) of the 16 children survived for at least 1 year after transplantation. Two children with hepatoma died 13 and 14 months after transplantation. of carcinomatosis. One child died 26 months after transplantation with obstruction at the choledochocholechostomy: in this patient inability to enter dilated biliary radicals during percutaneous transhepatic cholangiography was incorrectly interpreted as assurance against the presence of biliary obstruction. One teenager died 6 years after liver replacement for Wilson's disease. This transplant 


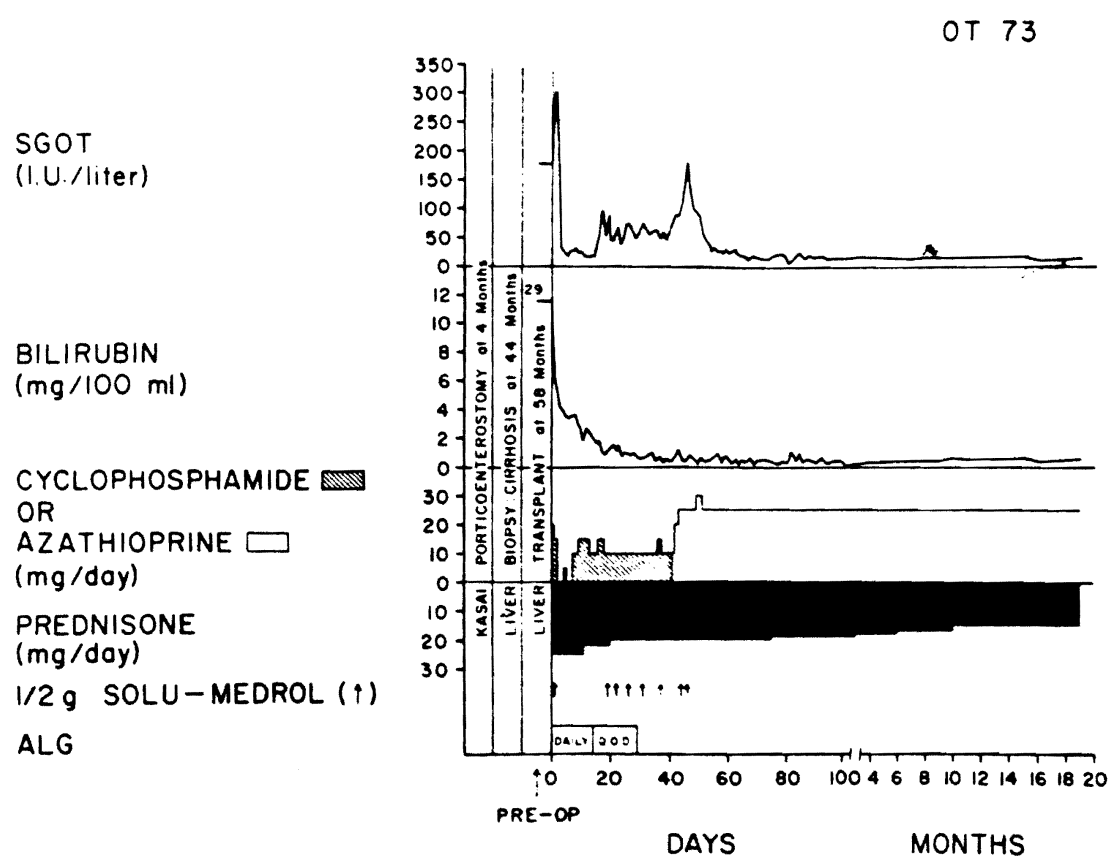

Figure 5. The course of a child with biliary atresia in whom the porticoenterostomy of Kasai had failed to relieve her jaundice. She is now alive 2 years after hepatic transplantation and has completely normal liver function. (By permission of Josiah Macy, Jr. Foundation.)

had completely corrected the serum copper and ceruloplasmin levels and had partially normalized the urine copper excretion. The cause of death was chronic rejection and partial biliary obstruction.

Five of the 16 patients transplanted for diseases other than biliary atresia are still alive 1 to $4^{1 / 2}$ years after transplantation. Their primary diseases were chronic aggressive hepatitis (three), Wilson's disease (one), congenital biliary cirrhosis (one), and alpha-1-antitrypsin deficiency (one).

The results of liver replacement in these children in which potential follow-up is at least 1 year after transplantation are summarized in Table 2.

Table 2. Fifty-Six Pediatric Liver Transplants: Mortality During the First Year After Transplantation

\begin{tabular}{lcc}
\hline & $\begin{array}{c}\text { Biliary } \\
\text { ATREsia (40) }\end{array}$ & $\begin{array}{c}\text { Nonbiliary } \\
\text { ATREsia (16) }\end{array}$ \\
\hline Deaths from vascular complications & 10 & 1 \\
Deaths from early rejection & 5 & 2 \\
Deaths from nonvascular intraabdominal complications & 7 & 3 \\
Deaths from infection & 7 & 0 \\
Deaths from recurrent cancer & 0 & 1 \\
1 year survisal & $11: 40$ & 916 \\
& $(28$ percent & (56 percent) \\
\hline
\end{tabular}




\section{CONCLUSIONS}

Kidney transplantation in very young children, less than 2 years of age. has usually failed, mainly because of difficulties maintaining these patients on hemodialysis long enough to permit retransplantation after loss of the original graft.' Liver replacement in the very young child has been associated with a higher frequency of vascular and biliary obstruction than in the older child. due to the small size of these structures. Such accidents have contributed to unsatisfactory results with biliary atresía.

Transplantation of kidney or liver into older children has been more successful than transplantation of these organs into adults. Related or cadaveric kidney transplantation in the child has been followed by at least a 60 per cent patient survival for 6 to 13 years and a very acceptable quality of life. Liver replacement for diseases other than biliary atresia has been followed by a 56 per cent 1-year survival rate, and two children have survived for more than 5 years.

\section{REFERENCES}

1. DeShazo, C. V.. Simmons, R. L.. Bernstein. D. M.. DeShazo, M. M.. Willmert. J.. Kjellstrand. C. M. and Najarian. J. S.: Results of renal transplantation in 100 children. Surgery. $76: 461.1974$.

2. Lilly. J. R., and Starzl. T. E.: Liver transplantation in children with biliary atresia and vascular anomalies. J. Ped. Surg. 9:707. 1974.

3. Lilly. J. R. Giles. G.. Hurwitz. R. et al.: Renal homotransplantation in pediatric patients. Pediatrics. 47:548. 1971

4. Starzl. T. E.: Experience in Renal Transplantation. Philadelphia. W. B. Saunders Co., 1964.

5. Starzl. T. E., and Putnam. C. W.: Experience in Hepatic Transplantation. Philadelphia, W. B. Saunders Co., 1969

6. Starzl. T. E.. Marchioro. T. L.. Morgan. W. W.. and Waddell. W. R.: A technique for use of adult renal homografts in children. Surg. Gynec. Obstet.. 119:106. 1964.

7. Starzl. T. E.. Ishikawa. M.. Putnam. C. W. et al.: Progress in and deterrents to orthotopic liver transplantation; with special reference to survival, resistance to hyperacute rejection. and biliary tract reconstruction. Transplant. Proc.. 6(Suppl. 1):129. 1974.

8. Starzl, T. E., Marchioro. T. L.. Porter. K. A.. et al.: The role of organ transplantation in pediatrics. PED. CLIN. N. AM.. 13:381. 1966

9. Starzl. T. E.. Porter. K. A., Halgrimson. C. G.. et al.: A decade follow-up in early cases of renal homotransplantation. Ann. Surg., 180:606. 1974.

10. Starzl. T. E.. Porter. K. A.. Husber:. B. S.. et al.: Renal homotransplantation. Part 1. Curr. Probl. Surg., April. 1974.

11. Starzl. T. E.. Porter. K. A.. Husberg. B. S.. et al.: Renal homotransplantation. Part II. Curr Probl. Surg.. May. 1974.

12. Starzl. T. E.. Porter, K. A.. Putnam. C. W.. et al. : Liver Replacement in Children. Proceedings of the Josiah Macy. Jr. Foundation. Paris. 1975 (in press).

University of Colorado Medical Center

4200 East Ninth Avenue

Denver. Colołado 80220 